\title{
Medical education and the GMC: controlled or stifled?
}

\author{
Richard Smith
}

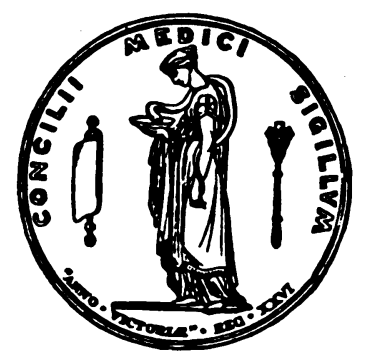

Many members of the GMC see regulation of medical education as the most important of the council's functions. Yet the division of the council that looks after education has a staff of only three and absorbs less than $5 \%$ of the council's budget. This limited effort may reflect the feeling within the council that undergraduate education is in good shape and that postgraduate education is primarily the responsibility of other bodies, particularly the royal colleges.

Certainly the council's work on medical education does not result in anything like the controversies arising over its disciplinary procedures. Yet among recent medical graduates there is widespread dissatisfaction with medical education, and Britain has not experienced the innovation in medical education that has been seen in countries like Canada, Australia, the United States, and The Netherlands. Coles recently reviewed the development of undergraduate medical education in Britain and concluded:

... medical education in the United Kingdom became reorganised in the middle of the 19th century by act of parliament, but ...this, and subsequent recommendations by the General Medical Council and others have done little to solve its perennial problems. In particular ... many students feel overloaded, lose their early motivation, some even becoming cynical, fail to see relevance in much of what they are taught, and are not able to retrieve their preclinical knowledge in a clinical setting.'

Failure, disappointment, "survival," "humiliation," and "stuckness" seem to be the key features in the accounts of those who have looked closely at British medical education. ${ }^{1-5}$ For instance, an ad hoc group of medical educators wrote in an open letter to the GMC in 1984:

We believe that British medical education is failing in two respects: firstly, in the extent to which it equips doctors with the capacity to think critically for themselves; and, secondly, in the degree to which it inculcates a broad, holistic, and sensitive outlook towards the health of both individuals and communities."

But at the same time medical researchers are worried about the scientific failures of medical education. In addition, continuing education gives rise to anxieties, with mutterings about the need for recertification. The GMC may need to try harder.

\section{Composition of the education committee}

Charged with "promoting high standards of medical education and coordinating all stages of medical education," the education committee of the GMC has long had considerable control over undergraduate medical education, but the Medical Act 1978 extended its influence to postgraduate education. Interestingly, the act also made the education committee independent of the council. This independence was not intended by the Merrison committee, which examined the GMC and produced proposals for a new medical act, ${ }^{7}$ but was achieved through some clever political footwork as the bill passed through parliament. The old guard of the GMC resented the idea that the elected members of the council might control the education committee, which

\section{London WC1H 9JR}

BrMed f 1989;298:1372-5 assistant editor was thought to belong rightly to the academics. In addition-and unlike most of the council's other committees - the education committee has a majority of non-elected members.

Some doctors - for instance, Dr David Gullick, who was an elected member of the council-object to the education committee being independent and dominated by non-elected members, but since 1978 its independence has not been actively used. The education committee reports to the council, and educational issues are debated at its meetings. The academics may, however, sleep easier in their beds because of the knowledge that the elected members will not be able to dictate to them.

The committee currently has 27 members: eight elected members, six university representatives, six representatives of the royal colleges, one lay member, and five co-opted members-including one from the Medical Council of Ireland. The president of the GMC is an ex officio member of the committee. The various sections of the GMC elect their representatives each year, and, in the words of the head of the education division, "education is very popular." Each year about a third of the membership of the committee changes. Many of the representatives of the elected members of the council are themselves academics.

Richard Wakeford, a medical educationist working at Cambridge and Leicester Universities, argues that the minimal representation on the committee of non-academics helps to make it a "profoundly conservative" body. The tendency to conservatism is increased by the committee working by consensus and consulting all interested parties before issuing recommendations. Wakeford also argues that the whole apparatus is too incestuous: "Deans and professors organise curricula, deans and professors sit on the committee, the committee makes recommendations, it seeks the views of other deans and professors and approves curricula, and so it goes - round and round with little intervention from the outside world." $\mathrm{He}$ also thinks that the committee should include (or have access to) specialists in education: "Many of the committee's tasks should surely benefit from educational, psychological, and psychometric fact." The committee does have one such member at the moment, but this is by chance rather than statutory design.

One idea raised during my discussions was that the committee might contain representatives of the main consumers of medical education-students. Many academic bodies within universities now contain students, but the head of the division said that the idea of including students had never been discussed and "would, of course, require a change in the medical act."

The education committee currently has two subcommittees - a small one that looks at examination returns and a larger one with 18 members that is looking at the council's "new" requirement to coordinate all the stages of medical education. In addition, an ad hoc working party is producing recommendations on continuing education, and another is being set up to revise the recommendations on basic medical education. 

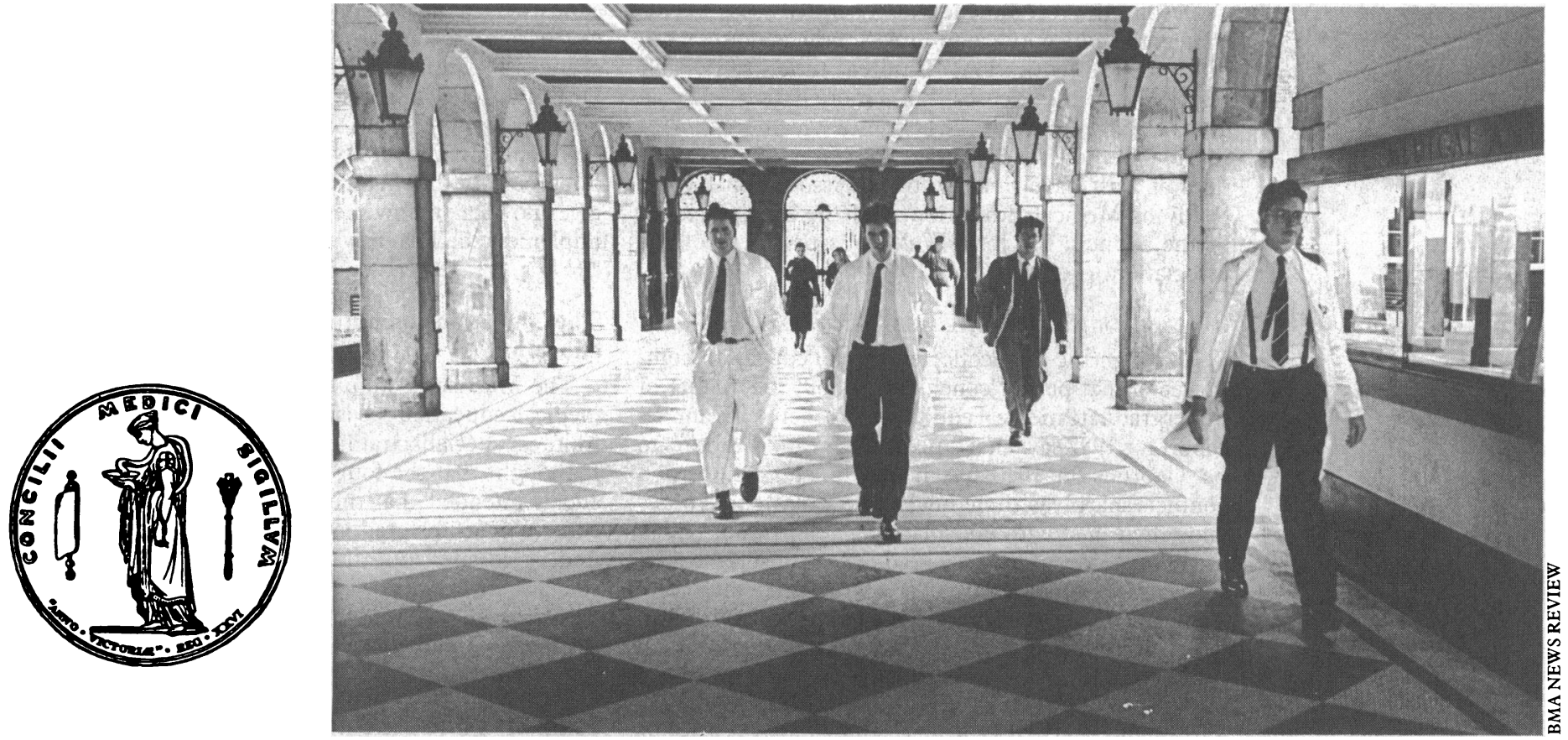

Innovation in undergraduate medical education may be inhibited by the General Medical Council

The education committee and undergraduate education

The starting point of the education committee is to recommend what is required from the various stages of medical education. Since its inception it has done so for basic medical education at roughly 10 year intervals: the last set of recommendations was published in $1980^{8}$ and the next will be available early in the 1990s. As required by the medical act the recommendations cover the knowledge and skill required for primary qualifications, the standard of proficiency required from candidates at the qualifying examination, and the patterns of experience that may be suitable for the preregistration year.

\section{VISITING AND INSPECTING MEDICAL SCHOOLS}

Armed with the recommendations on basic medical education, the GMC has approved the British medical schools and their qualifying examinations. The education committee has the power to visit medical schools and investigate the "sufficiency of the instruction... and any other matters relating to the instruction." This power was used in visiting the new medical schools in Southampton, Leicester, and Nottingham and the new clinical school in Cambridge, but it has not been used since.

Another power - to inspect the qualifying examinations of the medical schools-also fell into disuse until the Royal College of Physicians complained in 1982 that some British candidates for the membership examination seemed to have received an inadequate basic medical education. This inspired the GMC to begin a round of inspections - for the first time since the 1950s. The committee can conduct only three inspections a year and will thus take a decade to work through the medical schools. Its team consists of four doctors - a physician, a surgeon, and two others - who do not have to be members of either the education committee or the GMC. The council is short of obstetricians and gynaecologists and commonly has to call them in from the outside. The team spends about a week inspecting the examinations and then produces a report, which is not published, for the education committee. .

The team often includes the one member of the education committee who is something of a specialist in education, but, Richard Wakeiord thinks, the inspectors might benefit from more access to educational skills.

If the inspection throws up only minor problems the report is forwarded by the education committee to the medical school for its observations. Once returned the report is forwarded to the Privy Council. What might happen if the inspection threw up major problems is theoretical because this has not happened: the inspectors have not found the substantial problems that worried the Royal College of Physicians. The education committee does, however, have the power to recommend to the Privy Council that a medical school's qualifying examination should no longer be recognised. These extreme powers have never been used-except in one rather technical case featuring an Irish qualification. Some suggest that the committee should have lesser powers in addition, but Sir John Walton, the immediate past president of the council, argues that the threat of disapproval of a qualifying examination is in itself a lesser power.

\section{COLLECTING INFORMATION}

The education committee also collects routine information from the medical schools and royal colleges on curricula and examinations and advises medical schools on the acceptability of any changes. The data are published in the bound minutes of the council but contain little of interest. They do not, for instance, allow any judgment of the quality of medical schools: the committee seems resistant to information that might even be interpreted as such. Nor do they contain any data collected from students. These deficiencies led Professor Michael Simpson, a psychiatrist turned educationist, ${ }^{2}$ to describe the data at a meeting of the Association for the Study of Medical Education as "the bland leading the bland."

The committee has also published two substantial surveys of educational processes in undergraduate schools. Again, however, they give little information on quality and do not contain recommendations. Nor do the reports survey educational processes, and educationists argue that the committee has little idea how to evaluate a curriculum. ${ }^{9}$ They give a horrible impression of data being collected for their own sake rather than with any clear aim, although they contain information on whether the schools are implementing the council's recommendations. 


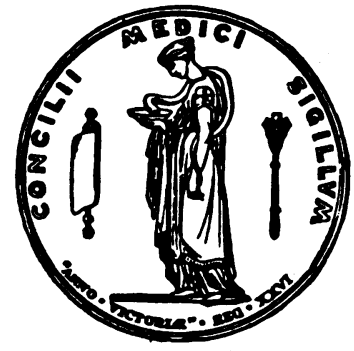

Despite the recommendation of the Merrison committee ${ }^{4}$ the education committee conducts no research into medical education. Limited time, staff, and resources are the excuses, but a more entrepreneurial ethos might mean that the committee teamed up with outside bodies to encourage research The council does at least have links with the Association for the Study of Medical Education, and the past president of the council, Sir John Walton, is president of the association.

\section{STATE OF UNDERGRADUATE MEDICAL EDUCATION}

Although the data collected by the education committee do not permit conclusions about the quality of undergraduate medical education, the council's annual report for 1987 says that "medical education appears to be vigorous in British schools." conflicts sharply with the analyses of Coles' and Horder and others $s^{5}$ and with information given to Isobel Allan during a survey of medical graduates sponsored by the Department of Health: most of the graduates were critical of the education that they had received. Similarly, at a recent Ciba Foundation symposium on training medical researchers a speaker who described undergraduate medical education as a "depressing anti-intellectual experience" was applauded as was one who said that one of the main teaching techniques used by medical educators was humiliation.

A main problem with undergraduate medical education is that it is too full. The education committee has long recognised this. Indeed, a council report in 1863 described "an overcrowding of the curriculum followed by results injurious to the student," and an 1869 report said that "Some limit must be assigned to the amount of knowledge that can be fitly exacted." The council's 1980 recommendations on basic medical education stated that "The council has urged in previous recommendations that means must be found of reducing congestion and overcrowding in the medical curriculum by instructing less and educating more." "Yet the committee has gone on recommending what might be included in the curriculum without recommending what might be thrown out, "which is clearly what is needed, and the new president is known to favour a problem solving rather than "pot filling"

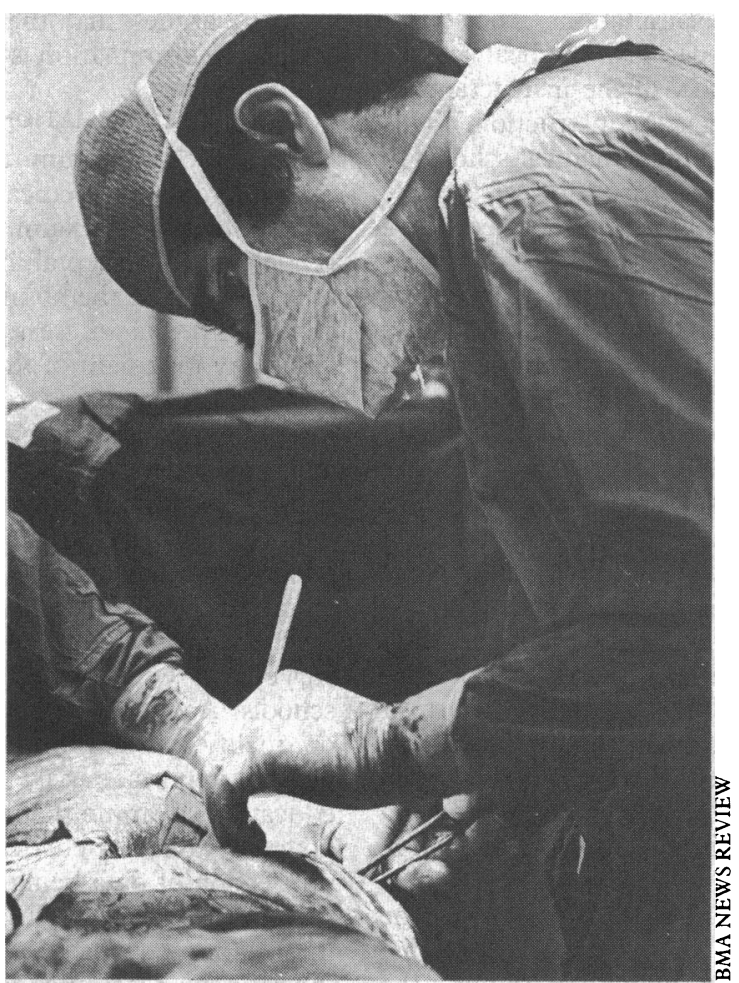

educational style. We must wait to see whether he can use the cumbersome GMC machinery to initiate radical changes in British undergraduate medical education. Dr Colin Coles, a senior lecturer in medical education who is working with the new medical course at Southampton University, says that "few people would disagree with the rhetoric of the GMC, but the council gives no idea on how their recommendations might be implemented. That is where the failure lies."

\section{The education committee and postgraduate education}

The Merrison committee recognised four stages of medical education-basic education, general clinical training, specialist training, and continuing education.? It thought that the four must fit seamlessly together, and it intended that the GMC should have as much control over postgraduate medical education as over undergraduate education. The power of the royal colleges ensured, however, that this did not happen. Thus the only power that the council has over postgraduate qualifications is its ability to refuse to register them, which is minor.

\section{GENERAL CLINICAL TRAINING}

The Merrison committee concluded that "the preregistration year cannot be regarded as a satisfactory period of education to deal with the important task of making a clinician of the graduate; and its unsatisfactoriness owes much to grave organisational weaknesses apparent in the control of the year." complained to the committee that their preregistration jobs were much more about service than education: they worked long hours and had little or no educational supervision.

Fourteen years later there is little evidence that conditions are any better, ${ }^{12}$ and it is highly likely that increasing pressure on the health service has made them worse. Progress has been made on paper: the education committee has produced recommendations on general clinical training (the preregistration year). ${ }^{13}$ One feature of them is to emphasise the importance of an educational supervisor modelled on the trainer in general practice.

Horder and others argued that general clinical training should last for at least two years, providing supervised experience of a wide range of clinical problems, formal teaching on subjects such as communication, and time to review skills. ${ }^{5}$ Within present circumstances this seems like crying for the moon, and a recent survey of the educational experience of senior house officers in one region showed the most glaring deficiencies. ${ }^{14}$ The education committee did a few years ago recommend a second non-mandatory year of general clinical training, but this recommendation was roundly rejected by the profession. The GMC lacks the political muscle, passion, and know how to make the changes that might be needed.

The council also lacks powers to ensure that its recommendations are followed. It does under the 1978 act have the power to visit "any approved hospital or approved institution," but it has not done so. Furthermore, all it could do would be to report any deficiencies to the university which had approved the post: the council has no power to stop the full registration of the unfortunate young doctor who has occupied one of these deficient posts. The council has, however, repeatedly urged the universities to withdraw recognition from unsatisfactory posts.

Similarly, the GMC has no power over resources, and it is inadequate resources that have put such pressure on junior hospital posts. A former chairman of the education committee has wrung his hands over the problem of limited resources in the annual report of
The General Medical Council has only limited control over specialist education 


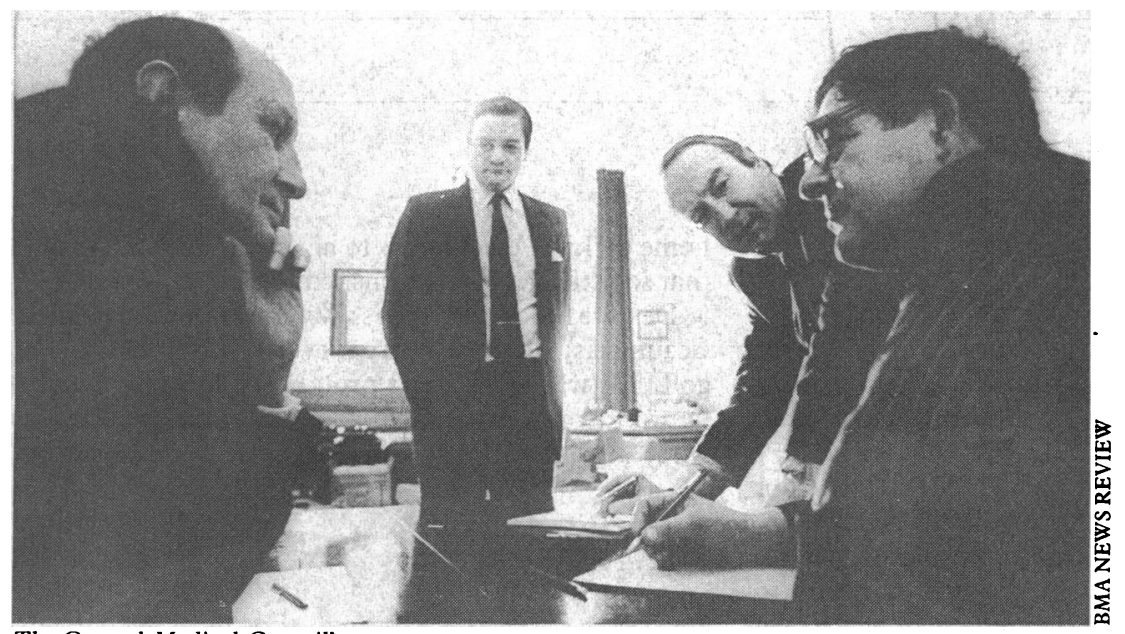

The General Medical Council's plans for continuing medical education are not yet complete

the council, , writing to the government complaining that educational standards were being compromised by lack of resources. The response has not been impressive.

\section{SPECIALIST TRAINING}

In October 1987 the education committee produced recommendations on the training of specialists, ${ }^{16}$ an event that Sir John Walton, the past president of the council, described as a watershed. These recommendations, which were pushed through in the face of opposition from the royal colleges, are intended to complement the recommendations by the royal colleges and faculties, emphasising the educational elements common to all the specialties (and for these purposes the GMC follows the Merrison committee in regarding general practice as a specialty). As with the recommendations on general clinical training the council has few powers to make these recommendations stick. And again there is no information on how the proposals might be implemented. The council has not commissioned an cxpert to produce proposals on implementation, nor has it run training courses to examine approaches to making the recommendations work. Some people have the skills to implement recommendations, but the GMC does not use them.

\section{SPECIALIST REGISTER}

One point of friction between the GMC and the royal colleges and faculties is whether it should keep a specialist register. At present the medical register does not indicate whether a doctor is a fully qualified specialist, but it does record that he or she has passed certain postgraduate examinations. The tussle over this issue is reminiscent of the argument in the last century on whether there should be a council to record a basic qualification.

The Merrison committee recommended that there should be a specialist register, ${ }^{+}$favouring an indicative register that recorded whether somebody was a specialist but not the specialty, as would a restrictive register. Without such a register there is nothing to stop doctors declaring themselves to be specialists after general registration, and this happens in private practice. Indeed, the anxiety that the proliferation of private practice might lead to more unsuitably trained people purporting to be specialists has increased the enthusiasm of the GMC for a specialist register. The main reason for the council wanting such a register is, however, that it would provide the means for it to control postgraduate education. And for this reason the royal colleges are unhappy about a specialist register. Because of the difficulty of reaching agreement in the profession the Medical Act 1978 did not include Merrison's recommendations for a specialist register, although it is likely to come eventually.

\section{CONTINUING EDUCATION}

The education committee has yet to produce its recommendations on continuing education, and it is not sure what form they will take. Certainly, it will need to recognise the very different conditions of hospital and general practice. Continuing education relates clearly to the important questions of audit and competence, and a past chairman of the committee has written that specialist trainees should "engage constructively in mutual and personal audits." "This recommendation, however, lacks teeth: without new powers the GMC cannot do anything about a doctor who refuses to engage in audit or peer review. The government has also made it plain in its review of the NHS that it wants all doctors to engage in audit,${ }^{17}$ and it could use financial power to implement its proposals, reducing the importance of the GMC.

A failure to implement efficient audit might lead to further calls for reregistration. The Merrison committee was attracted by the idea but did not examine it in depth. A system of reregistration would naturally complete the GMC's control of all stages of medical education.

\section{Conclusion: informal powers and stultification}

The GMC thus has responsibility for coordinating all stages of medical education but has real power over only basic medical education. And even this power is not exercised much. As the Merrison committee observed, the education committee tends to try to achieve its ends without using its formal powers: “...the informal aspects of the GMC's work in controlling the standards of medical education are probably the most significant aspects. That will no doubt continue to be the case." Thus the regular meetings of representatives of all the medical schools, the conferences, the sociability of these occasions, the endless consultation, the value placed on consensus, the limitations on interferences from "outsiders," and the collection of only the blandest data ensure that medical education develops slowly and smoothly. These mechanisms have, however, prevented any radical experiments and have meant that medical education develops much more slowly than medicine itself. The existence of the GMC may have maintained standards but at the price of stultifying British medical education.

1 Coles C. A study of the relationship between curriculum and learning in undergraduate medical education [PhD thesis.] Southampton: University of Southampton, 1985.

2 Simpson. MA. Medical education: a critical approach. London: Butterworth, 1972.

3 Pickering G. Quest for excellence in medical education. Oxford: Nuffield Provincial Hospitals Trust, 1979.

4 Maddison DC. What's wrong with medical education? Med Educ 1978;12 97-106.

5 Horder J, Ellis J, Hirsch S, et al. An important opportunity: an open letter to the General Medical Council. BrMed F 1984;288:1507-11.

6 Medical Act 1983. London: HMSO, 1970.

7 Committee of Inquiry into the Regulation of the Medical Profession. Report. London: HMSO, 1975. (Cmnd 6018.) (Merrison report.)

8 General Medical Council. Recommendations on basic medical education. London GMC, 1980

9 Coles C, Gale Grant J. Curriculum evaluation in medical and health care education. Dundee: Association for the Study of Medical Education, 1985.

10 Crisp AH. Medical education. Annual report 1987. London: GMC, 1988

11 McManus IC, Wakeford RE. A core medical curriculum. Br Med f 1989;298: 1051 .

12 McManus IC, Lockwood DNJ, Cruickshank JK. The preregistration year haos by consensus. Lancet 1977; i:413-7.

13 General Medical Council. Recommendations on general clinical training. London: GMC, 1987.

14 Grant J, Marsden P. Senior house officer training in south east Thames. London British Postgraduate Medical Federation, 1988.

15 Crisp AH. Medical education. Annual report 1986. London: GMC, 1987.

16 General Medical Council. Recommendations on the training of specialists. London: GMC, 1987.

17 Secretaries of State for Health, Wales, Northern Ireland, and Scotland. Working for patients. London: HMSO, 1989. (Cmnd 555.) 